\title{
EVALUACIÓN DE LA CAPACIDAD DE REMOCIÓN DE BACTERIAS COLIFORMES FECALES Y DEMANDA BIOQUÍMICA DE OXÍGENO DE LA PLANTA DE TRATAMIENTO DE AGUAS RESIDUALES “LA TOTORA”, AYACUCHO, PERÚ
}

\section{FECAL COLIFORM BACTERIA REMOVING CAPACITY ASSESSMENT AND BIOCHEMICAL OXYGEN DEMAND AT “LA TOTORA”, AYACUCHO, PERÚ, RESIDUAL WATERS TREATMENT PLANT}

\author{
Saúl A. Chuchón Martínez ${ }^{1}$ y Carlos A. Aybar Escobar ${ }^{1}$
}

\begin{abstract}
Resumen
La investigación se realizó entre los meses de Marzo a Julio del 2005 para determinar la capacidad de remoción de bacterias coliformes fecales (BCF) y la demanda bioquímica de oxígeno (DBO5) de la Planta de Tratamiento de Aguas Residuales (PTAR) "La Totora” de la ciudad de Ayacucho. Los análisis se realizaron en el laboratorio de Microbiología de la misma planta; donde se analizaron 70 muestras de agua. Para la cuantificación de la población de BCF, se aplicó la técnica de Tubos Múltiples de Fermentación (NMP); y el método respirométrico para determinar la DBO5. Con los resultados obtenidos, se calculó el porcentaje de remoción de BCF y DBO5 aplicando la siguiente fórmula: \% Remoción $=[(\mathrm{C}$ afluente $-\mathrm{C}$ efluente $) / \mathrm{C}$ afluente $] \times 100$. La capacidad de remoción de BCF de la PTAR "La Totora” fue del 99.9850\%, evacuando efluentes con una cantidad en promedio de 1.29 x 105 NMP/100 ml, siendo deficiente, pues para alcanzar una cantidad promedio de $<103$ NMP/100 ml de BCF (agua de clase III, Ley General de Aguas D.L. 17752) se requiere que la PTAR tenga una capacidad de remoción del orden del 99.9999\%; en tanto que la remoción de la DBO5 fue de 86.2\%, evacuando efluentes con $46.35 \mathrm{mg} / \mathrm{l}$, proceso deficiente en relación a lo estipulado por la Ley General de Aguas D.L. 17752 para aguas de clase III, que establece una concentración máxima de $15 \mathrm{mg} / \mathrm{l}$ que para alcanzar esta concentración serìa necesario una remociòn del orden del 95.5947\%.

Palabras clave: Remoción, coliformes fecales, demanda bioquímica de oxígeno, aguas residuales, planta de tratamiento de aguas residuales
\end{abstract}

\begin{abstract}
The research was conducted from March to July 2005 in order to determine the capacity of removing fecal coliform bacteria (FCB) and biochemical oxygen demand (BOD5) at "La Totora" Residual Waters Treatment Plant (RWTP) in the city of Ayacucho, Perú. Analyses were performed at the microbiology laboratory of the plant, where 70 water samples were analyzed. In order to quantify FCB, the Multiple Tube Fermentation (MTF) technique was employed and for BOD5, respirometry was used. With the results we calculated the percentage of FCB removal and BOD5 using the following formula: Removal\% $=[(\mathrm{C}$ affluent- $\mathrm{C}$ effluent $) / \mathrm{C}$ tributary $] \mathrm{x} 100$. The ability of BCF removal at "Totora" RWTP was 99.9850\%, evacuating effluents with an average amount of $1.29 \times 105 \mathrm{MPN} / 100 \mathrm{ml}$. This is poor, because to achieve an average amount of $<103$ MPN / 100 ml of BCF (Class III waters, General Law on Waters, DL 17752) RWTP should have a capacity of the removal of $99.9999 \%$. BOD5 removal was $86.2 \%$, with $46.35 \mathrm{mg} / \mathrm{l}$ evacuating effluents. This is also poor in relation to what is stated in the General Law on Waters. DL 17752 for Class III waters, which establishes a maximum concentration of $15 \mathrm{mg} / \mathrm{l}$. In order to attain this concentration a removal of about $95.5947 \%$ would be required.
\end{abstract}

Key words: Removal, fecal coliforms, biochemical oxygen demand, wastewater treatment plant sewage

\section{Introducción}

La planta de tratamiento de aguas residuales (PTAR) "La Totora" se ubica en la ciudad de Ayacucho capital de la Región del mismo nombre, a
$3.50 \mathrm{~km}$ del óvalo de la Magdalena, carretera Ayacucho - Huanta.

La capacidad de remoción de bacterias coniformes fecales (BCF) y remoción de la demanda bioquímica de oxígeno $\left(\mathrm{DBO}_{5}\right)$ por la PTAR “La Totora” se ve 
afectada por el crecimiento demográfico en la ciudad de Ayacucho haciendo que el volumen de agua residual a tratar sea cada vez mayor.

Estudios realizados por Consulting Engineers Salzgitter (CES, 2001), comprobaron que el estado que mostraba la PTAR "La Totora" no era satisfactoria ya que ésta trabajaba con un caudal significativamente mayor al de su capacidad de diseño, con una sobrecarga del $45 \%$, al tratar en promedio 260 l/s de agua cruda, situación que hacía que las unidades trabajaran deficientemente, por tal motivo se realizaron trabajos de modificación y ampliación en la planta.

Actualmente la PTAR "La Totora" cuenta con diversas unidades; para el tratamiento primario consta de 6 tanques Imhoff (4 de 30.50 x 17,80 m de dimensiones internas a los que se adicionaron el área de 30.10 × 12 m de dimensiones internas de los 2 tanques pre-existentes); para el tratamiento secundario cuenta con 4 biofiltros o filtros percoladores (diámetro interno de un FP de $32.00 \mathrm{~m}$, diámetro externo de la caja central de $3.10 \mathrm{~m}$, altura efectiva del material de relleno de $4.50 \mathrm{~m}$ y volumen disponible por FP de $3.585 \mathrm{~m}^{3}$ ) y dos lagunas facultativas (de 344 x $56 \mathrm{~m}$ con $35.100 \mathrm{~m}^{3}$ de volumen y 341 x $49 \mathrm{~m}$ con 29.700 $\mathrm{m} 3$ de volumen, respectivamente), todas las unidades de tratamiento secundario son operadas en forma paralela; finalmente poseen 3 lagunas de maduración que operan en serie (de 269 x 50 m con $24.000 \mathrm{~m}^{3}$ de volumen, 262 x $66 \mathrm{~m}$ con $32.000 \mathrm{~m}^{3}$ de volumen y $253 \times 70 \mathrm{~m}$ con $32.600 \mathrm{~m}^{3}$ de volumen, respectivamente) a partir de las cuales las aguas son evacuadas al río Alameda que actúa como cuerpo receptor; aguas abajo éstas son utilizadas para irrigación y bebida de animales.

La PTAR “La Totora”, ampliada, empezó a operar en Enero del 2004, sometiendo a tratamiento un promedio de $360 \mathrm{l} / \mathrm{s}$, por lo que se hacía necesario evaluar la capacidad de remoción de los principales indicadores (BCF y $\mathrm{DBO}_{5}$ ) y verificar si se ha logrado la mejora en la calidad de los efluentes, comparando los valores con las normas nacionales y valores guía de la OMS; para tal efecto se plantearon los siguientes objetivos:

- Determinar la capacidad de remoción de BCF y $\mathrm{DBO}_{5}$ de la PTAR “La Totora”.

- Cuantificar las BCF en afluentes intermedios y efluente final de la PTAR "La Totora".

- Determinar la $\mathrm{DBO}_{5}$ en afluentes intermedios y efluente final de la PTAR "La Totora”.

\section{Materiales Y Métodos}

Lugar experimental

El presente trabajo de investigación se realizó en el Laboratorio de Microbiología de la PTAR "La Totora” perteneciente a la Entidad Prestadora de Servicios de Saneamiento (EPSASA). El trabajo tuvo una duración de 5 meses comprendidos entre los meses de Marzo a Julio del año 2005.

Número de Muestras y Frecuencia de Muestreos

Las muestras fueron tomadas cada quince días a partir del mes de Marzo hasta el mes de Julio del 2005, haciendo un total de 70 muestras analizadas. Se realizaron muestreos de los afluentes y efluentes intermedios de la PTAR "La Totora" estableciéndose 07 puntos de muestreo: afluente de la planta de tratamiento (entrada), efluente del tanque Imhoff $\mathrm{N}^{\circ} 6$, efluentes de las lagunas facultativas 1 y 2 , afluente de los filtros percoladores, efluente de los filtros percoladores y efluente de la laguna de maduración $\mathrm{N}^{\circ}$ 3 (efluente de la planta).

\section{Métodos}

Para la cuantificación de BCF se utilizó la Técnica de Tubos Múltiples de Fermentación o Número Más Probable (APHA, 1992) y para la ddeterminación de la $\mathrm{DBO}_{5}$ se utilizó el método respirométrico haciendo uso de un sensor electrónico (Montgomery, 1967).

\section{Determinación de la Capacidad de Remoción}

Con los resultados de la cuantificación de coliformes fecales y la determinación de la $\mathrm{DBO}_{5}$, se calculó el porcentaje de remoción haciendo uso de la siguiente fórmula:

$$
\text { \% Remoción= }[(\mathrm{C} \text { afluente }-\mathrm{C} \text { efluente }) / \mathrm{C}
$$
afluente]x 100

Donde: C representa la concentración del parámetro. Análisis Estadístico

Con los datos obtenidos se calcularon los porcentajes de remoción de $\mathrm{BCF}$ y $\mathrm{DBO}_{5}$ cuyos resultados fueron presentados en histogramas.

Para la determinación de la unidad de tratamiento de mayor eficacia, los datos de remoción calculados fueron sometidos a la prueba estadística de TUKEY a través del programa SPSS versión 15.0.

\section{Resultados y Discusión}

Con los resultados que se muestran en la Figura 1 se observa que la capacidad de remoción de BCF en los tanques Imhoff en el período de estudio, se encuentran sobre los valores del parámetro de diseño (60\% de remoción). Observándose variaciones en el promedio de porcentajes de remoción entre los meses en estudio en un rango del 63.75 al $98.25 \%$ con valores más elevados de porcentaje de remoción en meses coincidentes con el incremento del personal para el monitoreo de la planta. La remoción de BCF en el tratamiento primario, tanques Imhoff, es principalmente por acción física, sedimentación, este proceso es influenciado por el periodo de retención del agua en la unidad de tratamiento, que en el caso de la PTAR “La Totora” aún no fueron estandarizados. 


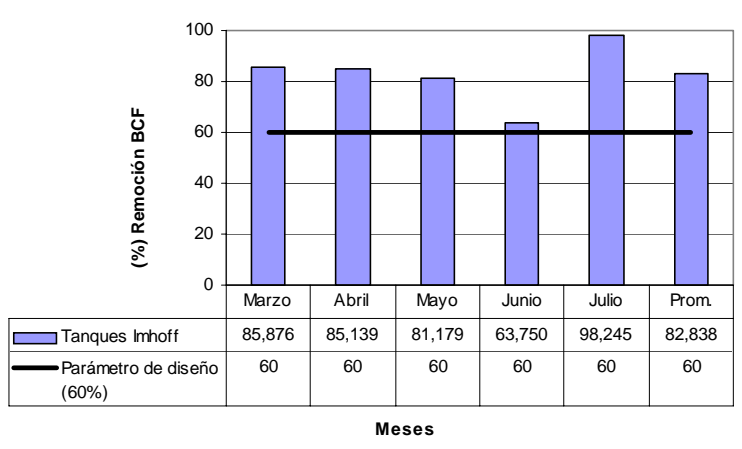

Figura 1. Porcentaje de remoción de bacterias coliformes fecales (BCF) de los tanques Imhoff de la PTAR "La Totora", Ayacucho - 2005.

El CEPIS-OPS (2005) manifiesta que el tanque imhoff es una unidad de tratamiento primario cuya finalidad es la remoción de sólidos suspendidos. El efluente que sale del tanque es de mala calidad orgánica y microbiológica. Por lo tanto, comparando con los valores obtenidos en el presente trabajo nos permitimos afirmar que los tanques Inhoff están operando de una manera adecuada desde el punto de vista de la remoción de BCF.

En el Figura 2, se observan los valores de la capacidad de remoción de la $\mathrm{DBO}_{5}$ de los tanques Imhoff, observándose que en los meses de Marzo, Abril y Mayo están por debajo del parámetro de diseño (25 \% de remoción de $\mathrm{DBO}_{5}$ ), con una tendencia de incremento de la capacidad de remoción. En los meses de Junio y Julio se observa un incremento en la capacidad de remoción de $\mathrm{DBO}_{5}$, con valores entre 35.1 al $42.1 \%$ de remoción, manteniéndose los valores por encima del parámetro de diseño, esta variación se debe al periodo de maduración de las unidades (más de 18 meses) como también al aumento de personal, los cuales se concentraron en la limpieza de natas en la cámara de sedimentación y cámara de ventilación, removiéndose gran cantidad de sólidos flotantes y materia orgánica que estuvo acumulándose en los últimos meses.

Tchobanoglous \& Burton (1995) reportan que una eficiencia típica de remoción de $\mathrm{DBO}_{5}$ para tanques Imhoff es de un 30 a un 35\%, valores que coinciden con los reportados para los dos últimos meses en el presente trabajo de investigación. Sin embargo el CEPIS-OPS (2005) manifiesta que el tanque Imhoff elimina del 40 al 50\% de sólidos suspendidos y reduce la DBO de 25 a 35\%. Debido a esta baja remoción de la DBO y coliformes, lo que se recomendaría es enviar el efluente hacia una laguna facultativa para que haya una buena remoción de microorganismos en el efluente.

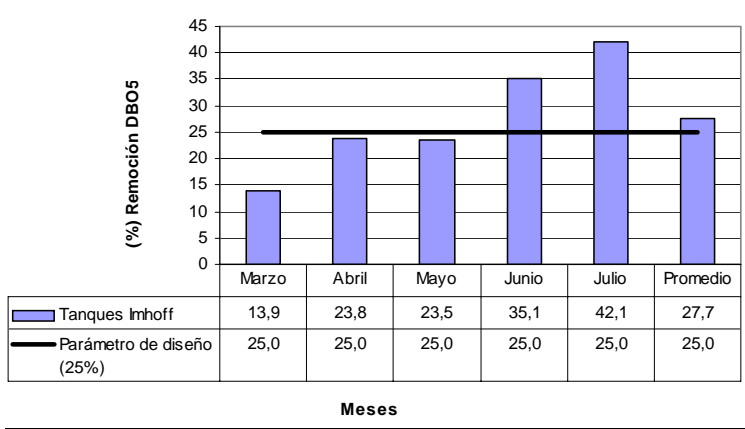

Figura 2. Porcentaje de remoción de DBO5 de los tanques Imhoff de la PTAR "La Totora", Ayacucho 2005.

En la Figura 3 se representa la capacidad de remoción de los filtros percoladores en lo que respecta a BCF, en los meses de Marzo a Abril, se mantuvieron por encima del valor del parámetro de diseño (90 \% de remoción de BCF). Se observó que el valor más bajo se dio en el mes de Julio con un 79.24\% de remoción. Originalmente el filtro es diseñado principalmente para la remoción de materia orgánica, la remoción de BCF se debe a que la comunidad biológica tan diversa presente en el filtro que está compuesta por bacterias facultativas aerobias y anaerobias, hongos, algas y protozoos actúan como competidores y/o depredadores.

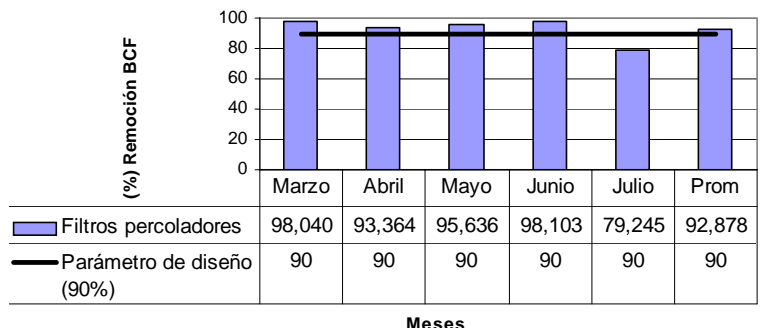

Figura 3. Porcentaje de remoción de BCF de los filtros percoladores de la PTAR "La Totora", Ayacucho - 2005.

En el Figura 4 se observa que la capacidad de remoción de $\mathrm{DBO}_{5}$ en los filtros percoladores se mantienen con valores por debajo del valor del parámetro de diseño (86\% de remoción de $\mathrm{DBO}_{5}$ ). Se observó que los valores más bajos se obtuvieron en los meses de Marzo con 56.7\% y Julio con un $60.3 \%$ de remoción de $\mathrm{DBO}_{5}$, estas variaciones se deben a que el agua ingresa con una alta carga de materia orgánica al filtro.

En el estudio previo a la ampliación de la PTAR “La Totora” realizado por CES (2001), definió como condición inicial la siguientes características de aguas a tratar: para el horizonte 2010 y 2020 valores de ingreso a la planta de $204 \mathrm{mg} / \mathrm{l}$ y $208 \mathrm{mg} / \mathrm{l}$ de $\mathrm{DBO}_{5}$ respectivamente, estos valores no representan la 
realidad porque los resultados obtenidos desde el mes de Marzo el agua residual cruda ingresa a la planta con valores de $\mathrm{DBO}_{5}$ Mayores a $250 \mathrm{mg} / \mathrm{l}$ (251.5 mg/l de $\mathrm{DBO}_{5}$ en Marzo) alcanzando en Julio el valor más alto con $408.5 \mathrm{mg} / \mathrm{L}$ de $\mathrm{DBO}_{5}$ como promedio mensual. Estos valores discordantes habrían generado un inadecuado dimensionamiento de las unidades de tratamiento, generando deficiencias en su capacidad de remoción.

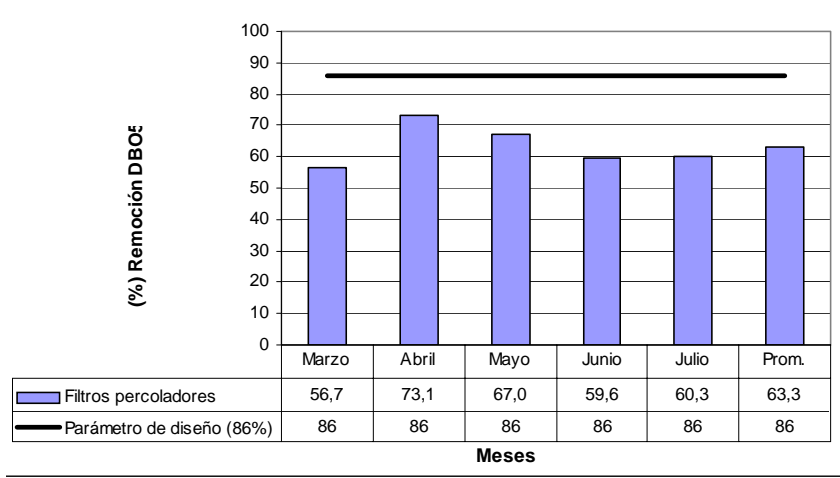

Figura 4. Porcentaje de remoción de la DBO5 de los filtros percoladores de la PTAR "La Totora", Ayacucho - 2005

Crites \& Tchobanoglous (2000) y Tchobanoglous \& Burton (1995), consideran una remoción adecuada de 80 a $90 \%$ de $\mathrm{DBO}_{5}$ para filtros percoladores. Platzer et al. (2002) manifiestan que las unidades del Biofiltro de la PTAR de la ciudad de Masaya en Nicaruaga, tienen una excelente remoción de materia orgánica, puesto que los porcentajes de remoción de DBO5 oscilan entre 89\% - 95\%; valores muy superiores a los establecidos en los diseños de la PTAR "La Totora” y los valores obtenidos en la presente investigación.

En la Figura 5 se observa que la capacidad de remoción de BCF de las lagunas facultativas 1 y 2 en el período de Marzo a Julio del 2005 (con valores entre 95.86 y $99.69 \%$ ) se mantienen por encima del valor establecido en el parámetro de diseño (90\% de remoción de BCF), esto debido al menor caudal con el que trabajan y el mayor tiempo de retención de las aguas sometidas a tratamiento que generan mayor grado de mortalidad $y$ el incremento de la sedimentación de las BCF. Von (1996), considera como característica de una laguna facultativa, una remoción de 60 a $99 \%$ para coliformes fecales, valores ligeramente menores a los hallados en el presente trabajo de investigación, indicando una eficiente capacidad de remoción de BCF de estas unidades. Por otro lado Botero et al. (2002) manifiesta que a pesar de presentar niveles de remoción de los indicadores bacterianos superiores al 99\%; durante el periodo de toma de muestras en las lagunas de estabilización, el $90 \%$ de las mismas no cumplieron con la normativa establecida por la OMS/OPS.
En la Figura 6 se observa que la remoción de la $\mathrm{DBO}_{5}$ de las lagunas facultativas 1 y 2 en el período de Marzo a Julio (con valores entre 52.4 a $60.7 \%$ ), se mantienen por debajo del parámetro de diseño (86\% de remoción de $\mathrm{DBO}_{5}$ ), estos valores se deben a que la laguna de maduración 1 y 2 están operando con caudales menores a los que se concibieron en el parámetro de diseño, aproximadamente $25 \mathrm{l} / \mathrm{s}$, actualmente vienen trabajando con caudales menores a $5 \mathrm{l} / \mathrm{s}$, este hecho incrementa el período de retención de las aguas en las lagunas generando una mayor propagación de la población algal, interfiriendo a la vez en la determinación de la $\mathrm{DBO}_{5}$, incrementando el valor calculado. El CEPIS-OPS (2005) manifiesta que en este proceso, en el que participan bacterias aerobias o facultativas, se originan compuestos inorgánicos que sirven de nutrientes a las algas, las cuales a su vez producen más oxígeno que facilita la actividad de las bacterias aerobias. Existe pues una simbiosis entre bacteria y algas que facilita la estabilización aerobia de la materia orgánica. El desdoblamiento de la materia orgánica se lleva a cabo con intervención de enzimas producidas por las bacterias en sus procesos vitales.

Este hallazgo es corroborado por Von (1996), que manifiesta que los sólidos en suspensión de las lagunas facultativas son en un 60 a $90 \%$ de algas, considera también que $1 \mathrm{mg}$ de algas genera una $\mathrm{DBO}_{5}$ cercana a $0.45 \mathrm{mg}$.

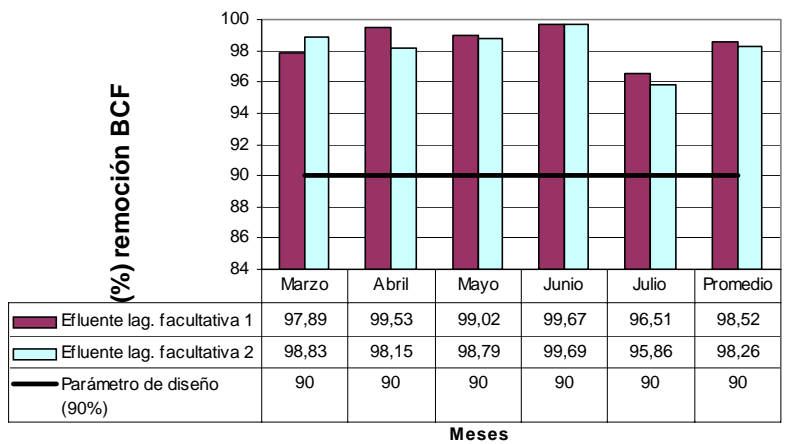

Figura 5. Porcentaje de remoción de BCF de las lagunas facultativas 1 y 2 de la PTAR "La Totora", Ayacucho 2005.

Por otro lado Rolim (2000) considera que la cantidad de algas en las lagunas de estabilización varía entre 40 y $30 \mathrm{mg} / \mathrm{l}$ (peso seco) y que la reducción de $\mathrm{DBO}_{5}$ de las lagunas facultativas es alrededor de $70 \mathrm{a}$ $90 \%$, valores coincidentes con lo indicado por Von (1996); sin embargo, estos valores son mayores a los hallados en el presente trabajo indicándonos que en cuanto a la remoción de $\mathrm{DBO}_{5}$, las lagunas facultativas de la PTAR "la Totora” están funcionando deficientemente. 


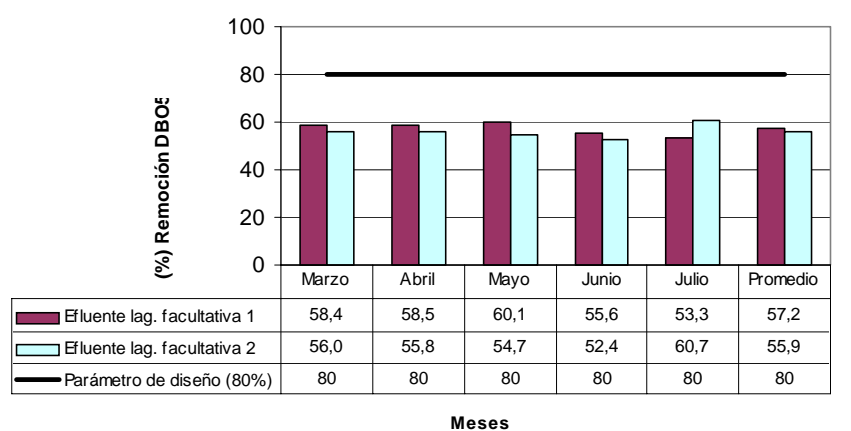

Figura 6. Porcentaje de remoción de la DBO5 de las lagunas facultativas 1 y 2 de la PTAR "La Totora", Ayacucho - 2005.

Por otro lado Cárdenas et al. (2002) manifiesta que las Lagunas de Estabilización representan una alternativa eficiente en el tratamiento de las aguas residuales, sin embargo su principal desventaja es la alta concentración de algas en el efluente; situación observada en el presente trabajo de investigación.

En la Figura 7 se observa que la capacidad de remoción de BCF en las lagunas de maduración en los meses de Marzo a Julio, presentaron valores que se mantuvieron muy por encima de los parámetros de diseño (25\% de remoción de coliformes fecales). Se observa que el promedio en la remoción de BCF es de un $96.82 \%$, valor que está muy por encima del parámetro de diseño (25\%).

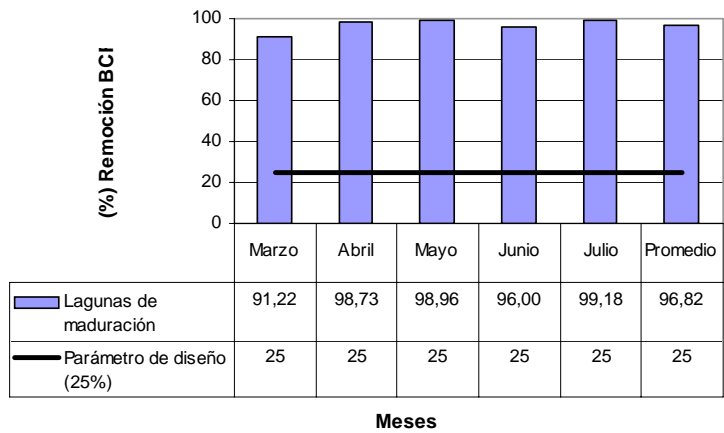

Figura 7. Porcentaje de remoción de BCF de las lagunas de maduración de la PTAR "La Totora", Ayacucho - 2005.

Von (1996) indica que las lagunas de maduración posibilitan una mejora en la calidad del efluente de cualquiera de los sistemas de tratamiento de aguas residuales. El principal objetivo es el de la remoción de patógenos y remoción adicional de $\mathrm{DBO}_{5}$. Las lagunas de maduración, constituyen una alternativa bastante económica en la desinfección del efluente en comparación a métodos más convencionales como la cloración.

En la Figura 8 se observa que la remoción de $\mathrm{DBO}_{5}$ de las lagunas de maduración, entre los meses de Marzo a Julio, presentaron valores, entre 25.57 y $57.60 \%$, que se mantuvieron muy por encima de los parámetros de diseño (16\% de remoción).

En la Figura 8 se observa que en el mes de Marzo se obtuvo el valor más bajo de remoción con un $25.57 \%$ para $\mathrm{DBO}_{5}$, esta variación se debe principalmente a la interferencias causadas por la biomasa algal y la presencia de natas la cual evidencia una posible saturación de lodos en los sedimentadores integrados. El promedio general de remoción de $\mathrm{DBO}_{5}$ fue de $46.47 \%$, valor que esta muy por encima del parámetro de diseño (16\% de remoción).

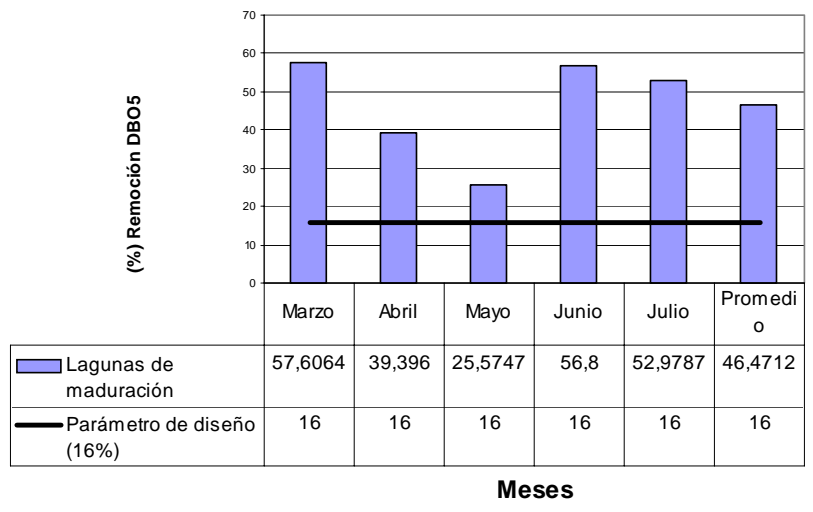

Figura 8. Porcentaje de remoción de DBO5 en lagunas de maduración de la PTAR "La Totora", Ayacucho - 2005.

Se inicia con la evacuación de lodos e intercalado de los sedimentadores a partir del mes de Mayo, se observa un incremento en la remoción de $\mathrm{DBO}_{5}$ que va de un $25.57 \%$ en el mes de Mayo a una remoción de $56.80 \%$ en el mes de Junio, esto explicaría el incremento de la remoción en estas lagunas.

Tchobanoglous \& Burton (1995), reportan que para estanques de estabilización (maduración), se considera como parámetro típico de diseño, una remoción de $\mathrm{DBO}_{5}$ de un 60 a $80 \%$ y cuyos principales productos de conversión son las algas, $\mathrm{CO}_{2}$, tejido celular bacteriano y $\mathrm{NO}_{3}$, con un tiempo de retención de 5 a 20 días. Estos datos no concuerdan con lo encontrado en el presente trabajo ya que los valores no llegan al 60\% de remoción, esto debido al tiempo de retención bastante corto (4 días) que se dan en estas unidades en la PTAR "La Totora”.

En la Figura 9 se observa que el promedio general en la remoción de BCF a nivel de planta es de 99.985\%, valores que están por encima del parámetro de diseño (99\%). Sin embargo se debe tener en cuenta que el porcentaje de remoción promedio de BCF es deficiente para alcanzar valores de $<10^{3} \mathrm{NMP} / 100 \mathrm{ml}$ para aguas de Clase III según la Ley General de Aguas D.L. 17752 y los valores guía de la OMS, para el cual 
sería necesario una remoción del 99.9999\%; teniendo en cuenta que estos efluentes son utilizados como agua de riego y para bebida de animales.

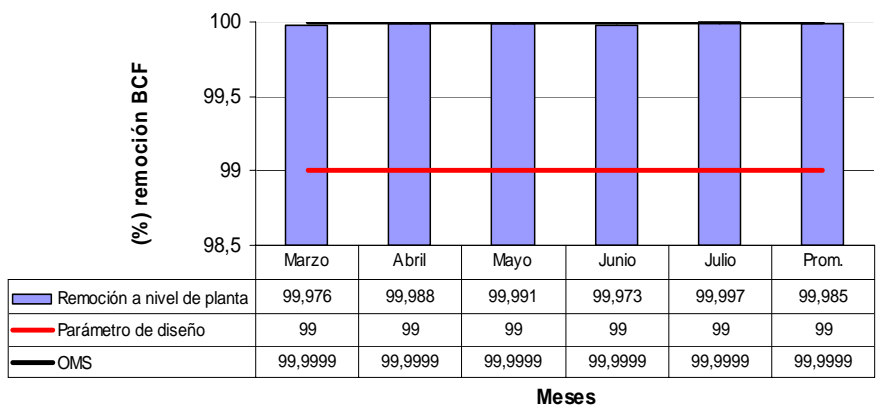

no mayores de $15 \mathrm{mg} / \mathrm{l}$ de $\mathrm{DBO}_{5}$, sería necesario una remoción del 95.59\%.

Como se evidencia en la Tabla 1 , la unidad de tratamiento de mayor capacidad de remoción de la DBO5 son los filtros percoladores con un valor del $63.17 \%$, la unidad de menor capacidad de remoción son los tanques Inhoff con un promedio del $27.157 \%$.

De los resultados de la prueba de Tukey mostrados en la Tabla 2 se concluye que el sistema de lagunas facultativas son las unidades que mejor remueven las BCF (97.08\%), las unidades que menos remueven las BCF son los tanques Imhoff con un

Figura 9. Porcentaje de remoción de BCF de la PTAR "La Totora", Ayacucho - 2005.

Considerándose como disposición final el vertido, la legislación involucrada corresponde a la Ley General de aguas del Perú (Decreto Ley N 17752), que establece que los vertidos de aguas residuales tratadas no deberán afectar las condiciones de uso del río. Dado que el río Alameda ha sido identificado como uso de riego, el efluente de la planta de tratamiento deberá ser tal que la calidad del río aguas abajo se ajuste a un agua de Clase III (aguas para riego de vegetales y de consumo crudo y bebida de animales).

En estudios similares, Morillo \& Botero (2005) determinan un porcentaje de remoción para BCF del orden del $92.5 \%$ con una carga de estas bacterias de $3.4 \times 10^{4} \mathrm{NMP} / 100 \mathrm{ml}$ en los efluentes de la PTAR de la ciudad de Maracaibo. Situación similar a lo observado en el presente trabajo de investigación.

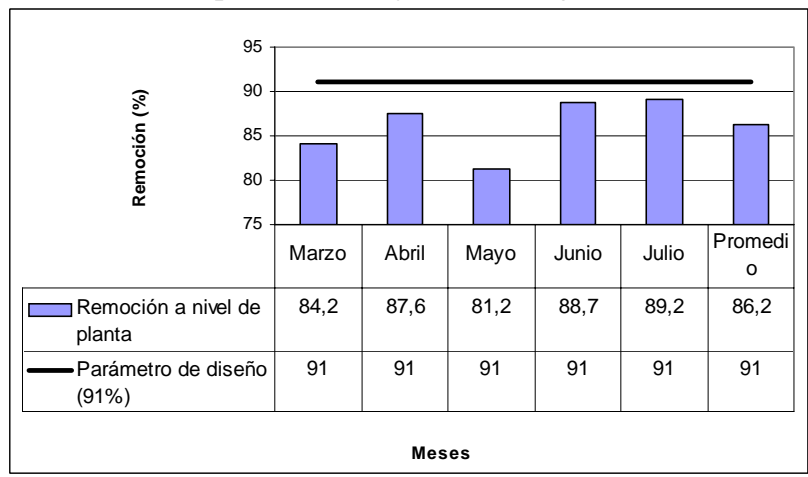

Figura 10. Porcentaje de remoción de la DBO5 de la PTAR "La Totora", Ayacucho - 2005.

En la Figura 10 se observa que el promedio general de remoción de $\mathrm{DBO}_{5}$ es de $86.16 \%$ (con un valor de la $\mathrm{DBO}_{5}$ del efluente de $46.35 \mathrm{mg} / \mathrm{L}$ ), valor que está por debajo del parámetro de diseño (91\%); según a lo establecido en la Ley General de aguas del Perú, para aguas de Clase III, la cual establece valores promedio del $77.97 \%$.

Tabla 1. Prueba de Tukey de comparación de porcentajes de remoción de DBO5 entre las distintas unidades de tratamiento de la PTAR “La Totora” - Ayacucho 2005.

DBO

Tukey B $\mathrm{B}^{\mathrm{a}}$
\begin{tabular}{|l|r|r|r|r|r|}
\hline & & \multicolumn{3}{|c|}{ Subconjunto para alfa $=.05$} \\
\cline { 3 - 6 } & $\mathrm{N}$ & 1 & 2 & 3 & 4 \\
\hline Tanidad Operativa & 10 & 27,157 & & & \\
Laguna de maduración & 10 & & 46,349 & & \\
Laguna facultativa 2 & 10 & & 55,727 & 55,727 & \\
Laguna facultativa 1 & 10 & & 56,828 & 56,828 & \\
Filtros percoladores & 10 & & & 63,171 & \\
Planta & 10 & & & & 85,855 \\
\hline
\end{tabular}
Se muestran las medias para los grupos en los subconjuntos homogéneos.
a. Usa el tamaño muestral de la media armónica = 10,000.

Tabla 2. Prueba de Tukey de comparación de porcentajes de remoción de BCF entre las distintas unidades de tratamiento de la PTAR “La Totora” - Ayacucho 2005.

Coliformes

\begin{tabular}{|c|c|c|c|}
\hline \multirow[b]{2}{*}{ Unidad Operativa } & \multirow[b]{2}{*}{$\mathrm{N}$} & \multicolumn{2}{|c|}{$\begin{array}{c}\text { Subconjunto para alfa } \\
=.05\end{array}$} \\
\hline & & 1 & 2 \\
\hline Tanques inhoff & 10 & 77,9722 & \\
\hline Filtros percoladores & 10 & 87,2707 & 87,2707 \\
\hline Laguna facultativa 2 & 10 & & 96,4142 \\
\hline Laguna de maduración & 10 & & 96,7943 \\
\hline Laguna facultativa 1 & 10 & & 97,0982 \\
\hline Planta & 10 & & 99,9772 \\
\hline
\end{tabular}

\section{Conclusiones}

1. La capacidad de remoción de BCF de la PTAR "La Totora" fue del 99.9850\%, evacuando efluentes con una cantidad en promedio de 1,29 x $10^{5} \mathrm{NMP} / 100 \mathrm{ml}$, siendo deficiente, pues para alcanzar una cantidad promedio de $<10^{3} \mathrm{NMP} / 100$ $\mathrm{ml}$ de BCF (agua de clase III, Ley General de Aguas D.L. 17752) se requiere que la PTAR tenga una capacidad de remoción del orden del 99.9999\% 
2. El porcentaje de remoción de la $\mathrm{DBO}_{5}$ de la PTAR "La Totora” fue del 86.2\%, evacuando efluentes con $46.35 \mathrm{mg} / \mathrm{l}$, proceso deficiente en relación a lo estipulado por la Ley General de Aguas D.L. 17752 para aguas de clase III, que establece una concentración máxima de 15 mg/l que para alcanzar esta concentración sería necesario una remoción del orden del 95.5947\%.

3. Las aguas efluentes de la PTAR "La Totora” aún no pueden ser consideradas como agua de Clase III (para riego de vegetales de consumo crudo y bebida de animales) de acuerdo a la Ley General de aguas del Perú DL. № 17752.

\section{Agradecimientos}

A la Entidad Prestadora de Servicios de Saneamiento EPSASA - Ayacucho, por facilitar el acceso a los laboratorios y brindarnos los reactivos y equipos para la realización del presente trabajo de investigación.

Al Ing. Edwin Iván Rodríguez Quispe, Jefe de la PTAR "La Totora”, al Blgo. Rudesindo Huincho Rodríguez, Jefe del Área de Control de Calidad de EPSASA, profesionales que colaboraron con el presente trabajo.

\section{Literatura citada}

American Public Health Association. (APHA) American Water Works Association. Water Pollution Control Federation. 1992. Métodos normalizados para el análisis de aguas potables y residuales. Ediciones Días de Santos S.A. 17 edición. USA.

Botero L., Zambrano L., Oliveros C., León D., Sarcos M. \& Martínez M. 2002. Calidad microbiológica del agua de un sistema de lagunas de estabilización a ser empleada en irrigación. Rev. Fac. Agron. 19(4): 312-323.
CEPIS-OPS. 2005. Guía para el diseño de tanques sépticos, tanques Inhoff y lagunas de estabilización. OPS/CEPIS/05.163. Lima Perú.

Cárdenas C., Tomas P., Araujo C. \& Yabroudi S. 2002. Mejoramiento del Efluente de Lagunas a través de un Filtro Rocoso. XXVIII Congreso Interamericano de Ingeniería Sanitaria y Ambiental. Cancún, México.

Consulting Engineers Salzgitter (CES) GMBH. 2001. Estudio de impacto ambiental proyecto de agua potable y alcantarillado de Ayacucho. Volumen II, Tomo I.

Consulting Engineers Salzgitter (CES) GMBH. 2002. Estudio definitivo - informe final proyecto de agua potable y alcantarillado de Ayacucho.

Crites R. \& Tchobanoglous G. 2000. Tratamiento de aguas residuales en pequeñas poblaciones. Editorial Mc Graw - Hill Interamericana. Bogotá - Colombia.

Montgomery H.A.C. 1967. The determination of biochemical oxygen demand by respirometric methods. Water Res. 1/1: 632-640.

Morillo A. \& Botero L. 2005. Evaluación de la remoción de colifagos y bacterias indicadoras de contaminación en la Planta de Tratamiento Sur de aguas servidas de la ciudad de Maracaibo. CIENCIA. 13(2): 147-161. Maracaibo, Venezuela.

Platzer M., Cáceres V. \& Fong N. 2002. Investigaciones y experiencias con biofiltros en Nicaragua, Centro América. XXVIII Congreso Interamericano de Ingeniería Sanitaria y Ambiental Cancún, México, 27 al 31 de octubre.

Rolim S. 2000. Sistema de Lagunas de estabilización. Editorial Mc Graw - Hill Interamericana. Bogotá Colombia.

Tchobanoglous G. \& Burton F. 1995. Ingeniería de aguas residuales, Tratamiento, Vertido y Reutilización. METCALF y EDDY. Inc Vol. I. Tercera edición. Editorial Mc Graw Hill. España.

Von M. 1996 .Lagunas de estabilización. Departamento de Ingeniería Sanitaria y Ambiental. Universidad Federal de Minas Gerais. Editorial SEGRAG. Brasil.

\footnotetext{
${ }^{1}$ Universidad Nacional De San Cristóbal de Huamanga, Av. Universitaria S/N, Ciudad Universitaria, Facultad de Ciencias Biológicas, Ayacucho - Perú. schuchonm@hotmail.com; caybar_escobar@hotmail.com
} 